\title{
JHPS-KARP-ARPS Joint Program for Commemoration of 2021 Bo Lindell Medal to Discuss the Future of Radiation Protection among Young Scientists and the Award Recipient, Dr. Ogino
}

\author{
Toshioh Fujibuchi', Haruyuki Ogino ${ }^{2}$, Han Ki Taek ${ }^{3}$, Kotaro Tani ${ }^{4}$, Daniel Emes ${ }^{5}$ \\ ${ }^{I}$ Department of Health Sciences, Faculty of Medical Sciences, Kyushu University, Fukuoka, Japan; ${ }^{2}$ Division of Radiation Protection Policy Planning, \\ Department of Radiation Protection, Japanese Nuclear Regulation Authority, Tokyo, Japan; ${ }^{3}$ Radiation Instrument Standardization Research Center, Korean \\ Association for Radiation Application, Jeongeup, Korea; ${ }^{4}$ Department of Radiation Measurement and Dose Assessment, National Institutes for Quantum and \\ Radiological Science and Technology, Chiba, Japan; ${ }^{5}$ Radiation Consulting Australia, Cockatoo Valley, SA, Australia
}

\section{Letter}

Received April 1, 2021

Revision May 4, 2021

Accepted May 12, 2021

Corresponding author:

Toshioh Fujibuchi

Department of Health Sciences, Faculty of Medical Sciences, Kyushu University, 3-1-1, Maidashi, Higashi-ku, Fukuoka, Japan

E-mail: fujibuchi.toshioh.294@m.

kyushu-u.ac.jp

(iD https://orcid.org/0000-0001-9713-6155

\begin{abstract}
This is an open-access article distributed under the terms of the Creative Commons Attribution License (http://creativecommons.org/licenses/by-nc/4.0), which permits unrestricted use, distribution, and reproduction in any medium, provided the original work is properly cited.
\end{abstract}

Copyright $\odot 2021$ The Korean Association for Radiation Protection

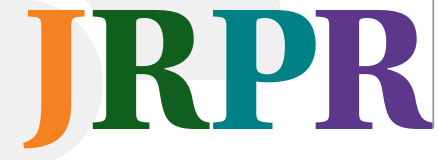

Dr. Haruyuki Ogino, a member of the Japan Health Physics Society (JHPS), was awarded the 2021 Bo Lindell Medal by the International Commission on Radiological Protection (ICRP). To commemorate this, the "Joint JHPS-KARP-ARPS program for young radiation protection (RP) scientists to discuss the future of RP" was organized via a web meeting system. First, Dr. Ogino gave a lecture, and then young researchers selected from each academic society made presentations on the future of RP. After the presentations by the three researchers, a free talk was heldyoung researcher groups of each country being active is a great opportunity to collaborate and exchange information. It was emphasized that the low awareness of knowledge related to radiation has been common to all of the participating countries. Thus, it is necessary to utilize communication via web technology, as done for this program, effectively. One of the biggest advantages for Asia and Oceania is that we do not have a significant time difference. The round-table discussion was concluded by expressing the hope of active exchange and development of young researchers in the future.

Keywords: Bo Lindell Medal Award, Radiological Protection, Round-Table Discussion, Young Researcher

Date: February 26 (Fri.), 2021, 13:00-14:00, JST

Venue: Online (Zoom)

Presenters:

- Special Guest: Dr. Haruyuki Ogino (Japanese Nuclear Regulation Authority, NRA Japan)

- KARP: Dr. Ki Taek Han, (Korean Association for Radiation Application, KARA)

- JHPS: Dr. Kotaro Tani (National Institutes for Quantum and Radiological Science and Technology, QST)

- ARPS: Dr. Daniel Emes (Radiation Consulting Australia)

Chair: Prof. Toshioh Fujibuchi (Kyushu University, Editor of JRPR) 


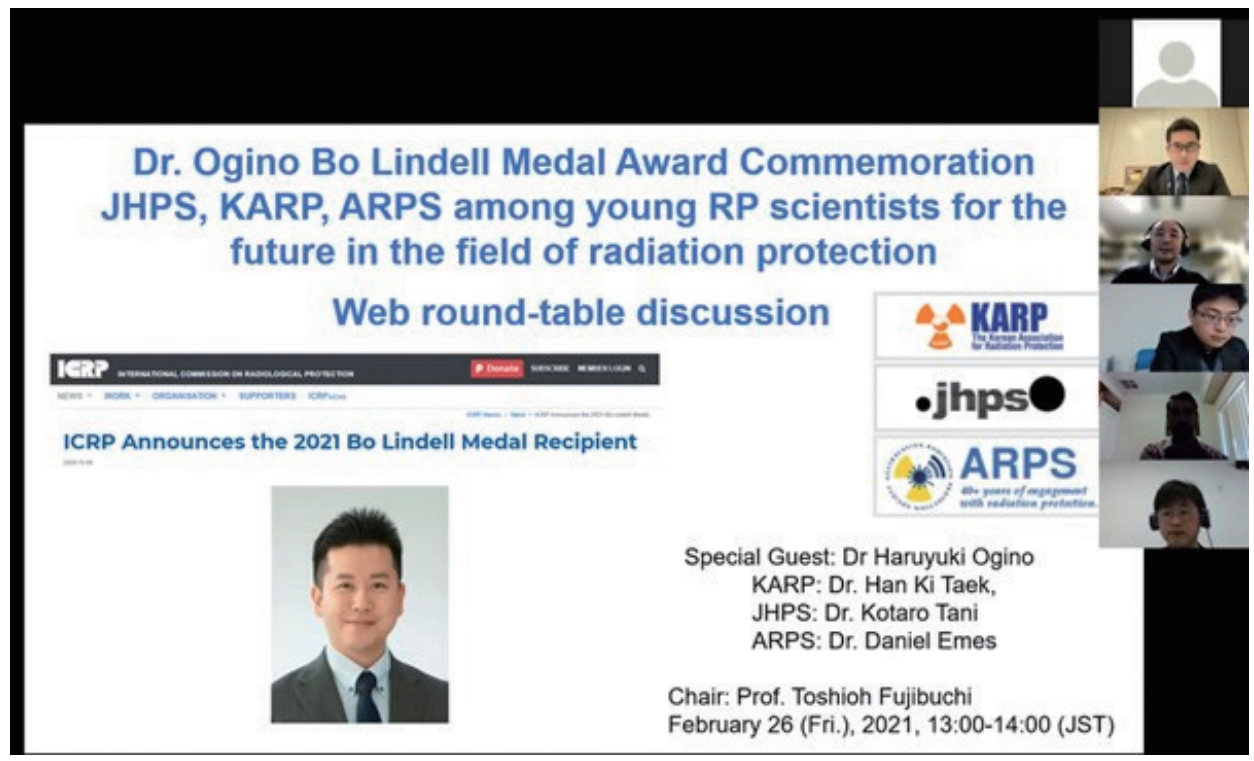

Fig. 1. Round-table discussion start screen.

Dr. Haruyuki Ogino, a member of the Japan Health Physics Society (JHPS), was awarded the 2021 Bo Lindell Medal. To commemorate this, the "Joint JHPS-KARP-ARPS program for young radiation protection (RP) scientists to discuss the future of RP" was organized via a web meeting system (Fig. 1).

The International Commission on Radiological Protection (ICRP) established the Bo Lindell Medal for the promotion of radiological protection (also known as radiation protection, or RP) in 2017. It honors the memory and dedication of Bo Lindell, who served as ICRP Scientific Secretary 1957-1962, Main Commission member 1963-1985, and Chairman 19771985. Lindell made many important contributions to RP, including playing a central role in the development of the 1977 Recommendations (Publication 26), the core of which forms the foundation of RP today. The Medal is thus given to an early- to mid-career individual making a significant contribution to the promotion of RP, conferred once every 2 years on the occasion of ICRP's biennial symposia on the RP system.

As part of the round-table discussion, first, Dr. Ogino gave a lecture entitled "Toward the Promotion of Radiation Protection by Expanding Academia Network in Asia and Oceania." After introducing himself, he gave a background on the Medal and talked about expectations for the academia network of young RP researchers in Asia and Oceania. He described his career switch from a researcher to regulator and his experience with the Young Researchers' Network at JHPS. For the expansion of the academia network, based on his ex- perience, Dr. Ogino said he considers building relationships based on mutual trust that allow a frank exchange of views regardless of positions as important. It is not enough to simply know each other by face; it is important to have a deep understanding of each other and of the other person's expertise. He expressed the hope that relationships among young researchers are developed and expanded to Asia and Oceania in the future.

Next, Dr. Ki Taek Han presented "The Activation Plan for Radiation Protection.” The major problems in the RP field are as follows: (1) negative image of RP, (2) lack of manpower and aging, (3) insufficient industry and government support, and (4) loss of opportunity for networking and interactions. To solve these, promoting a good image of RP, international education programs, online/offline mentoring and recruitment consulting, building human resource management, holding international workshops and seminars, and expanding award opportunities were mentioned as solutions. The Korean Association of Radiation Protection (KARP) young scientists' group (YSG) has around 80 members and is active in the subgroups of Radiation Protection Philosophy, Radiation Measurement/Dosimetry, Radiation Epidemiology, Radiation Protection in Medicine, and Radiation Emergency Management. YSG's roles and responsibilities in RP are very important. To promote a good image of RP, we should be conscious of consistency, ensuring consistent interest and support in the long run. The KARP YSG hopes to develop close cooperation with young professionals in other countries. 
Next, Dr. Tani presented the "Direction of the Radiation Protection Field." His research field is internal dose assessment, which usually provides equivalent and effective doses for the "reference person" through the following three steps: biokinetic model analysis, Monte Carlo simulation of radiation transport, and dose calculation. The current ICRP position (e.g., ICRP Publication 130) is that these doses may be used for both prospective and retrospective assessments; however, the latter means assessing doses using the results of individual/workplace monitoring in order to record individual doses and demonstrate compliance with regulatory requirements and not in order to determine the individuals' organ-specific risks.

Equivalent/effective dose used for RP does not provide individual-specific dose and it would be beyond the scope of $\mathrm{RP}$ to give advice on how to perform individualized retrospective dose assessments. Nevertheless, "How far can equivalent/effective dose be applied?" could be a discussion point to immediately identify those possibly needing medical follow-up from among those who had substantial exposure to radiation exceeding the prescribed dose limit. One idea is to determine a conservative borderline of equivalent/effective dose considering its uncertainties (such as the differences between the reference person and individuals, and the difference in radiation sensitivity among individuals), which can be applied for screening in the short term in a radiation emergency. While in the intermediate and/or long term, individualized dose assessments for the organs and tissues at risk should be performed for the identified individuals whose equivalent/effective dose has exceeded the conservative borderline. Individual dose assessment and/or subsequent medical follow-up would be the scope of radiation emergency medicine rather than RP, but further discussions on "How far can equivalent/effective dose be applied?" could be effective as a bridge between $\mathrm{RP}$ and radiation emergency medicine, to prepare for a future radiation emergency.

Finally, Dr. Emes presented the "Radiation Protection Future in Australia." One of the major issues before RP in Australia is public perception. There is a general fear of radiation in the island country, often leading to opposition to any kind of uranium mining, exploration, or nuclear activities-lack of education related to nuclear technology, radiation, and $\mathrm{RP}$ is certainly a factor here; also, there is little to attract students to RP. As a keen physics student growing up in Australia, it was apparent, Dr. Emes said, that radiation was a topic that was brushed aside in high school. Therefore, focus on the relevant education can hopefully increase interest in radiation safety and encourage young professionals to enter the radiation industry. The younger professionals who have a knack for marketing and social media could help improve public perception and dispel the "fear." This is the key to a thriving RP community in Australia-education will bring fresh faces into the industry, help reduce public fear, which will allow the implementation of more projects in Australia, and increase job prospects as a result.

What we can all do to help is to try and simplify concepts so that the general public can understand. Get out and communicate with different industries-the more face-to-face contact radiation professionals have with other industries, the better understood we will be; this includes collaborating with industries on RP projects. Listen to others' perspectives and then respond, regardless of position. Just because someone may lack education in an area does not mean that their views are worthless. Educate them, but be respectful of their views. Stay involved with the community.

After the presentations by the three researchers, a free talk was held-young researcher groups of each country being active is a great opportunity to collaborate and exchange information. It was emphasized that the low awareness of radiation has been common to all of the participating countries. Thus, it is necessary to utilize communication via web technology, as done for this program, effectively. One of the biggest advantages for Asia and Oceania is that we do not have a significant time difference.

The round-table discussion was concluded by expressing the hope of active exchange and development of young researchers in the future.

\section{Conflict of Interest}

No potential conflict of interest relevant to this article was reported.

\section{Author Contribution}

Conceptualization: Fujibuchi T. Project administration: Fujibuchi T. Writing - original draft: Fujibuchi T. Writing - review \& editing: Ogino H, Han T, Tani K, Emes D. Validation: Fujibuchi T. 